\title{
Differences in cognitive performance during pregnancy and early motherhood
}

Citation for published version (APA):

de Groot, R. H. M., Vuurman, E. F. P. M., Hornstra, G., \& Jolles, J. (2006). Differences in cognitive performance during pregnancy and early motherhood. Psychological Medicine, 36(7), 1023-1032. https://doi.org/10.1017/S0033291706007380

Document status and date:

Published: 01/01/2006

DOI:

10.1017/S0033291706007380

Document Version:

Publisher's PDF, also known as Version of record

\section{Please check the document version of this publication:}

- A submitted manuscript is the version of the article upon submission and before peer-review. There can be important differences between the submitted version and the official published version of record.

People interested in the research are advised to contact the author for the final version of the publication, or visit the DOI to the publisher's website.

- The final author version and the galley proof are versions of the publication after peer review.

- The final published version features the final layout of the paper including the volume, issue and page numbers.

Link to publication

\footnotetext{
General rights rights.

- You may freely distribute the URL identifying the publication in the public portal. please follow below link for the End User Agreement:

www.umlib.nl/taverne-license

Take down policy

If you believe that this document breaches copyright please contact us at:

repository@maastrichtuniversity.nl

providing details and we will investigate your claim.
}

Copyright and moral rights for the publications made accessible in the public portal are retained by the authors and/or other copyright owners and it is a condition of accessing publications that users recognise and abide by the legal requirements associated with these

- Users may download and print one copy of any publication from the public portal for the purpose of private study or research.

- You may not further distribute the material or use it for any profit-making activity or commercial gain

If the publication is distributed under the terms of Article $25 \mathrm{fa}$ of the Dutch Copyright Act, indicated by the "Taverne" license above, 


\title{
Differences in cognitive performance during pregnancy and early motherhood
}

\author{
R. H. M. DE GROOT ${ }^{1,2 *}$, E. F. P. M. VUURMAN², G. HORNSTRA ${ }^{1}$ AND J. JOLLES \\ ${ }^{1}$ Nutrition and Toxicology Research Institute Maastricht (NUTRIM), Maastricht University, \\ The Netherlands; ${ }^{2}$ Brain \& Behaviour Institute, Division of Cognitive Disorders, and Department of Psychiatry' \\ \& Neuropsychology, Maastricht University. The Netherlands
}

\begin{abstract}
Background. Pregnancy has often been associated with cognitive deficits, but results are equivocal and little is known about how these deficits progress with time.

Method. In the present study, the cognitive performance of 57 pregnant women was compared with that of 50 non-pregnant women matched for age and education, using a well-validated neurocognitive test battery at weeks 14, 17, 29, and 36 of pregnancy, and 32 weeks postpartum in the pregnant group and at comparable times in the non-pregnant group.

Results. Memory encoding and retrieval, as assessed with a word learning task, were significantly lower in the pregnant group than in the control group. This difference was still present at 32 weeks after delivery. The two groups did not differ in complex speed of information processing at any of the test moments; however, general speed of information processing was significantly compromised during early motherhood (week 32 postpartum).
\end{abstract}

Conclusion. Thus, memory performance is poorer during pregnancy and early motherhood, and general speed of information processing is slower during early motherhood.

\section{INTRODUCTION}

During the last decades there have been several reports that pregnancy acts upon cognitive function (Brett \& Baxendale, 2001), but the issue is far from settled. Some authors reported an impaired cognition during pregnancy (Poser et al. 1986; Silber et al. 1990; Brindle et al. 1991; Parsons \& Redman, 1991; Eidelman et al. 1993; Sharp et al. 1993; Buckwalter et al. 1999), while others did not find such an effect (Schneider, 1989; Morris et al. 1998). One study showed a relation between pregnancy and improved cognitive performance (Christensen et al. 1999).

In an earlier study we showed that memory performance, but not information processing

* Address for correspondence: R. H. M. de Groot, Ph.D., Maastricht University, Department of Psychiatry \& Neuropsychology, PO Box 616, 6200 MD Maastricht. The Netherlands.

(Email: RHM.deGroot a NP.unimaas, nl) speed, is compromised during early pregnancy (de Groot et al. 2003). Another study demonstrated a decrease in speed of information processing and attention tasks in women in late pregnancy (i.e. around delivery) (Buckwalter et al. 1999). These apparently discordant findings suggest that cognitive functioning may change during pregnancy and that the various cognitive functions may alter in different ways. Unfortunately, longitudinal data is sparse, and thus, a study in which the cognitive functioning of pregnant women is monitored during pregnancy with tests, measuring different aspects of cognition, is warranted. Therefore, the aim of the present study was twofold. First, potential differences in performance on a neurocognitive test battery covering different cognitive domains between pregnant women and women in a control group matched for age and education were examined. Second, it was investigated whether 
the various cognitive functions were affected differently during the various stages of pregnancy and the postpartum period.

A longitudinal case-control study was performed in which the cognitive performance of 57 pregnant women from week 14 of pregnancy until 32 weeks after delivery and that of 50 nonpregnant women matched for age and education over the same time period was monitored. A battery of tests measuring verbal memory and learning, attentional functions, and speed of information processing in simple and complex conditions was used. As the relation between pregnancy and cognition has not yet been clearly demonstrated this needs to be clarified before potential causal factors can be investigated.

\section{METHOD}

\section{Design}

The current study was part of an ongoing study investigating the role of essential fatty acid supplementation on pregnancy outcome. The supplement of the main study did not influence cognition (de Groot et al. 2004).

We tested a group of pregnant women, using a cognitive test battery, at weeks $14,17,29$, and 36 of pregnancy and at 32 weeks after delivery (hereafter referred to as week 72). The choice of the time schedule for test administration was based on practical considerations. Pregnant women were recruited by their midwife or gynaecologist. A first appointment in The Netherlands is always at week 12 of gestation. Therefore week 14 was the earliest moment the study could start. Hence it was not possible to investigate the effects of first trimester pregnancy on cognitive performance. The latest moment in pregnancy to test the subjects was week 36 of pregnancy, because deliveries between week 37 and week 42 are considered a term. Weeks 17 and 29 were chosen as intermediary. Week 32 after delivery was selected because previous research showed that fatty acid levels have stabilized by then (Otto et al. 2001). A non-pregnant control group matched for age and education was tested at comparable time intervals using the same procedure.

Four parallel versions of the cognitive test battery were used to measure cognitive performance during pregnancy. The version order was randomized over the total study population to exclude possible differences in level of difficulty between the four versions. Three parallel test versions were used at week 72 (randomized). Although some women dropped out from the study, the different test versions were still equally divided within the final study population.

All tests were administered approximately at the same time in the subject's home (no family members around, doorbell and telephone switched off). These precautions were taken to decrease the possible influence of environmental factors. In order to guarantee optimal quality of the test results, protocol violations were scored on a 6-point scale, varying from 'complete and reliable' to 'test not administered'. Only data of tests with a score 'complete and reliable' were included in the dataset. The tests were administered by two skilled investigators who were trained in test administration according to the procedure used in the Maastricht Aging Study (Jolles et al. 1995; van Boxtel et al. 1998). Such training has been shown to result in high inter-rater and intra-rater reliability. The Medical Ethics Committee of the University Hospital Maastricht approved the study and written consent was obtained from all participants.

\section{Study population}

Pregnant women were recruited by midwives in the region Maastricht, Heerlen, and Sittard, in the southeastern part of The Netherlands, and by the Departments of Obstetrics and Gynaecology of hospitals in the same area (University Hospital Maastricht, Atrium Medical Center in Heerlen, and Maasland Hospital in Sittard). The selection criteria were pregnancy of less than 14 weeks at study entry and good health, i.e. not suffering from any metabolic, cardiovascular, renal, psychiatric, or neurological disorders. Exclusion criteria were diastolic blood pressure higher than $90 \mathrm{mmHg}$, multiple pregnancy (women carrying more than one baby), and not being of Caucasian origin.

The non-pregnant control group was matched for age and education; the latter being considered a proxy for socioeconomic status (Currie et al. 1997; Lynch \& Kaplan, 2000; Lahelma et al. 2004). The subject's highest level of education was measured on an 8-point scale, 
ranging from primary education to higher vocational training and university (de Bie, 1987). To reduce the possible influence of socioeconomic differences between groups, where possible the women in the control group were friends or family members of the pregnant women; the other control subjects were recruited by means of advertisements in local newspapers. The inclusion and exclusion criteria were the same as for the pregnant population with exception of the pregnancy-related criteria. At the start of the study, the control participant's last pregnancy was at least 32 weeks ago and the participants did not intend to become pregnant during the study period (next 58 weeks).

A total of 80 pregnant and 59 non-pregnant women agreed to participate in the study. Pregnant women were over-sampled because of an increased probability of dropping out during the study (e.g. due to miscarriages). Of the 80 pregnant women, three entered the study before the set-up was ready and thus had incomplete data. Their data were excluded from analysis. One subject was excluded from the larger project for dietary reasons (she ate fish more than twice a week, which would influence fatty acid levels) and her data were also excluded from the analysis. During the study, 16 subjects dropped out: four subjects gave birth prematurely (before week 36 of gestation), seven subjects were insufficiently motivated (failed to show up on three successive appointments), one subject experienced severe morning sickness and did not want to continue the study, and four subjects dropped out for dietary reasons (disliked the supplement from the main study). After delivery, three women did not participate in the follow-up at week 72: one subject because of postpartum depression, one because of the loss of her baby, and one because she had moved away from the area. Thus final data analysis was based on data from 57 pregnant women.

In the control group, two of the 59 subjects were excluded at the start of the study because they used medication. Data were incomplete for seven subjects: four subjects became pregnant during the study and three subjects could not be reached in time for follow up. Thus data for 50 subjects in the control group were used in the final analysis.
Table 1. Subject characteristics (mean \pm s.D.)

\begin{tabular}{lcc}
\hline Characteristics & $\begin{array}{c}\text { Control group } \\
(n=50)\end{array}$ & $\begin{array}{c}\text { Pregnant group } \\
(n=57)\end{array}$ \\
\hline Agc $(\mathrm{yr})^{\mathrm{h}}$ & $30 \cdot 6 \pm 4 \cdot 2$ & $29 \cdot 9 \pm 3 \cdot 8$ \\
Education & $4 \cdot 4 \pm 1 \cdot 2$ & $4 \cdot 1 \pm 1 \cdot 5$ \\
Height $(\mathrm{cm})$ & $169 \pm 6$ & $769 \pm 5$ \\
Weight $(\mathrm{kg})$ & $71 \pm 14$ & $71 \pm 14$ \\
Number of children & 15 & 23 \\
0 & 9 & 26 \\
1 & 20 & 7 \\
2 & 3 & 1 \\
3 & 3 & 0 \\
$>3$ & 14 & 0 \\
Number of pregnancies & 10 & 19 \\
0 & 15 & 25 \\
1 & 8 & 7 \\
2 & 3 & \\
3 & &
\end{tabular}

Table 1 shows the subjects' characteristics. No statistically significant differences were found between the groups in terms of age, education, height, or weight. In addition all subjects had a steady partner.

\section{Cognitive test battery}

The following neuropsychological tests were chosen on the basis of earlier research into neurocognitive functioning in healthy subjects or subjects with mild cognitive complaints (Bohnen et al. 1992; Houx \& Jolles, 1993; Klein et al. 1996; Moller et al. 1998):

The Concept Shifting Test (CST). This is a test of behavioural planning and shifting (Vink \& Jolles, 1985; Houx, 1991). The test consists of four test sheets. On each test sheet, 16 small circles are grouped in a larger circle. On the first sheet numbers appear in a fixed random order, on the second sheet letters, and on the third sheet both. Subjects were requested to cross out the items in the right order $[1-2-3-4$ (subtask A), A-B-C-D (subtask B), $1 \mathrm{~A}-2 \mathrm{~B}-$ $3 \mathrm{C}-4 \mathrm{D}$ (subtask $\mathrm{C}$ ) respectively]; the time taken to do this was measured using a stopwatch. A fourth sheet with empty circles (subtask 0) which had to be crossed out as fast as possible was used to correct for motor speed (CST0). Mean speed for A and B, corrected for motor speed, was used as a measure of general information processing speed (CSTAB). 
Subtask C, also corrected for motor speed, was used as a measure of concept shifting ability (CSTC). The parallel test versions presented the items, which had to be crossed out in different orders.

The Stroop Color-Word Interference Test. This was used to test selective artention (Stroop, 1935; Klein et al. 1997). The test consists of three subtests, involving three cards displaying 40 stimuli each: colour names printed in black (subtask I), coloured patches (subtask II), and colour names printed in one of the other colours (subtask III). For subtask I subjects had to read aloud the printed items, for subtask II they had to name the colour of the patches, and for subtask III they had to name the ink colour of the printed words. The outcome parameters of this test were the times needed to complete each subtest. Mean speed for subtasks I and II was used as a measure of gereral information processing speed (Str 12). Subtask III was used as a measure of colour word interference susceptibility (Str3).

The Letter Digit Substitution Test (LDST). This is a modified version of the Symbol-Digit Modalities Test (Smith, 1968). It was used to measure basic information-processing speed. At the top of the test sheet, a box was presented with nine numbers coupled with nine letters in random order. Subjects were asked to copy as many corresponding numbers as possible to boxes on the rest of the page which contained only the letters. The total number of corresponding numbers copied in 1 minute was used as the dependent variable. For the parallel test versions the nine letters were mixed around.

Visual Verbal Word Learning Task (WLT). To assess learning capacity as well as recall and retrieval from long-term memory, a visual verbal word learning task (Brand \& Jolles, 1985) was completed by the subjects. A set of 15 words was presented in a fixed order at 2-second intervals in each of three trials. Each trial ended with a free recall. The items for the WLT in all test versions were all monosyllabic meaningful Dutch words that occur frequently (20-400 per million), are acquired early in life (before age 6 years), and easily evoke a mental image, in order to ensure parallel test versions. The test versions were administered in random order to the subjects in order to prevent subtle effects of possible version differences. The mean recall (WLTtot) over the first two trials was used as a measure of encoding. Twenty minutes after the last trial (within this time the tasks mentioned above were performed), the subjects were asked to reproduce the set of words (delayed recall WLTdr) to determine retrieval.

\section{Statistics}

Differences between the two groups in age, weight, and height were analysed with unpaired $t$ tests. A Mann-Whitney test was used to investigate the differences in educational level.

The neuropsychological test data were grouped for three aspects of cognitive functioning, namely Memory, General speed (of information processing), and Complex speed. These cognitive domains were chosen in view of earlier studies which have shown subtle changes on these variables and established criteria which have been proven to be effective in the evaluation of subtle age-related cognitive changes (de Groot et al. 2002) and health-related cognitive changes (van Boxtel et al. 1998; see also a reference manual of neuropsychological assessment, Lezak, 1995). Therefore CSTAB, Str12 and LDST were grouped as General speed, CSTC and Str3 as Complex speed, and WLTtot and WLTdr as Memory. The ANOVA repeated-measures procedure was used to test whether there was a difference in cognition between control non-pregnant women and pregnant women during pregnancy. Group ("pregnant 'or 'control') was used as between-subjects factor, and time (weeks 14, 17, 29, and 36) as within-subject factor. Interaction effects were studied to determine whether cognitive function changes with time differently in pregnant and non-pregnant women.

A planned comparison one-way ANOVA corrected for education was used to test whether there was a postpartum effect (effect of early motherhood) on cognition. In an additional analysis, we corrected this model for test performance at week 14 because initial performance might influence later performance.

Although education was not significantly different between the two groups, we decided to enter education as covariate in the models because it is an important confounder in this 
type of research. As one-way ANOVA revealed that the number of children and the number of experienced pregnancies were not significantly associated with cognitive performance, we decided not to include these variables in our models. The statistical package used for these analyses was SPSS10.0 for Windows (SPSS Inc., Chicago, IL, USA) and the significance level was set at $p<0.05$.

\section{RESULTS}

The results of the cognitive tests administered at the different times are shown in Fig. 1 and the results of the statistical analyses in Table 2.

\section{General speed}

During pregnancy, no significant differences were found between the women in the control group and the women in the pregnant group for all three tests measuring general speed, indicating that general speed was comparable for both groups. The within-subjects effects revealed a significant main effect for time both in the Str12 $(p=0.000)$ and the LDST $(p=0.023)$ groups, indicating a slightly better performance over time, probably representing a learning effect.

In the postpartum period, i.e. in early motherhood, performance on general speed tasks was significantly different between the pregnant and non-pregnant groups. Both CSTAB $[F(1,102)=6.979, p=0.010]$ and LDST $[F(1,104)=6.331, p=0.013]$ revealed significant differences, with the women in the control group performing better than the new mothers. The difference in Str 12 performance approached significance $[F(1,103)=3 \cdot 515, p=0 \cdot 064]$. Similar results were obtained after correction for initial (week 14) performance (CSTAB: $p=0.014$ : LDST: $p=0.014$ ). It looks as if the significant difference reported for the CSTAB at week 72 is due to a greater improvement in performance in the control group than in the pregnant/mother group. However, this did not appear to be the case, since a one-way ANOVA on the delta scores showed that there were no statistically significant differences between the two groups in performance improvement $(p>0.05)$.

\section{Complex speed}

Performance on the complex speed tasks was not significantly different between the two groups of women, neither during pregnancy nor after delivery. A significant main effect of time was found in $\operatorname{Str} 3(p=0 \cdot 000)$, again representing a learning effect.

\section{Memory}

Significant between-subjects effects were found for the encoding task, as measured with the WLTtot $[F(1,103)=5 \cdot 110, p=0 \cdot 026]$, and the retrieval task, as measured with the WLTdr $[F(1,103)=5 \cdot 038, p=0 \cdot 027]$, indicating that the pregnant women performed significantly worse than the control women did. Within-subject analysis revealed a significant main effect of time $(p=0.044)$ in the WLTtot, indicating that performance on encoding improved over time in both groups. No time $\times$ group interactions were observed.

Postpartum, the new mothers still had a poorer encoding (WLTtot) performance than the control women $[F(1,102)=4.776, p=0.031]$, and the differences in retrieval (WLTdr) approached significance $(p=0-059)$. An analysis with test performance at study entry revealed comparable results (WLTtot: $p=0 \cdot 000$ ).

\section{DISCUSSION}

No differences in general speed of information processing were found between pregnant and non-pregnant women. However, postpartum the formerly pregnant women performed significantly worse than the control women. Complex speed of information processing was not different between the two groups at any time. Memory encoding and retrieval appeared to be compromised in pregnant women relative to non-pregnant women, and this difference was still found 32 weeks after delivery. Thus, memory performance is lower during pregnancy and early motherhood, whereas general speed of information processing is affected during early motherhood only. Consequently, slowness in information processing develops after pregnancy, and in addition to the memory deficit.

Interestingly, earlier studies provided some indication that information processing was affected in early motherhood. Harris et al. (1996) tested 20 pregnant women at week 36 of pregnancy and at 48 hours and 4 weeks after delivery, using the adapted DSST (Digit Symbol 

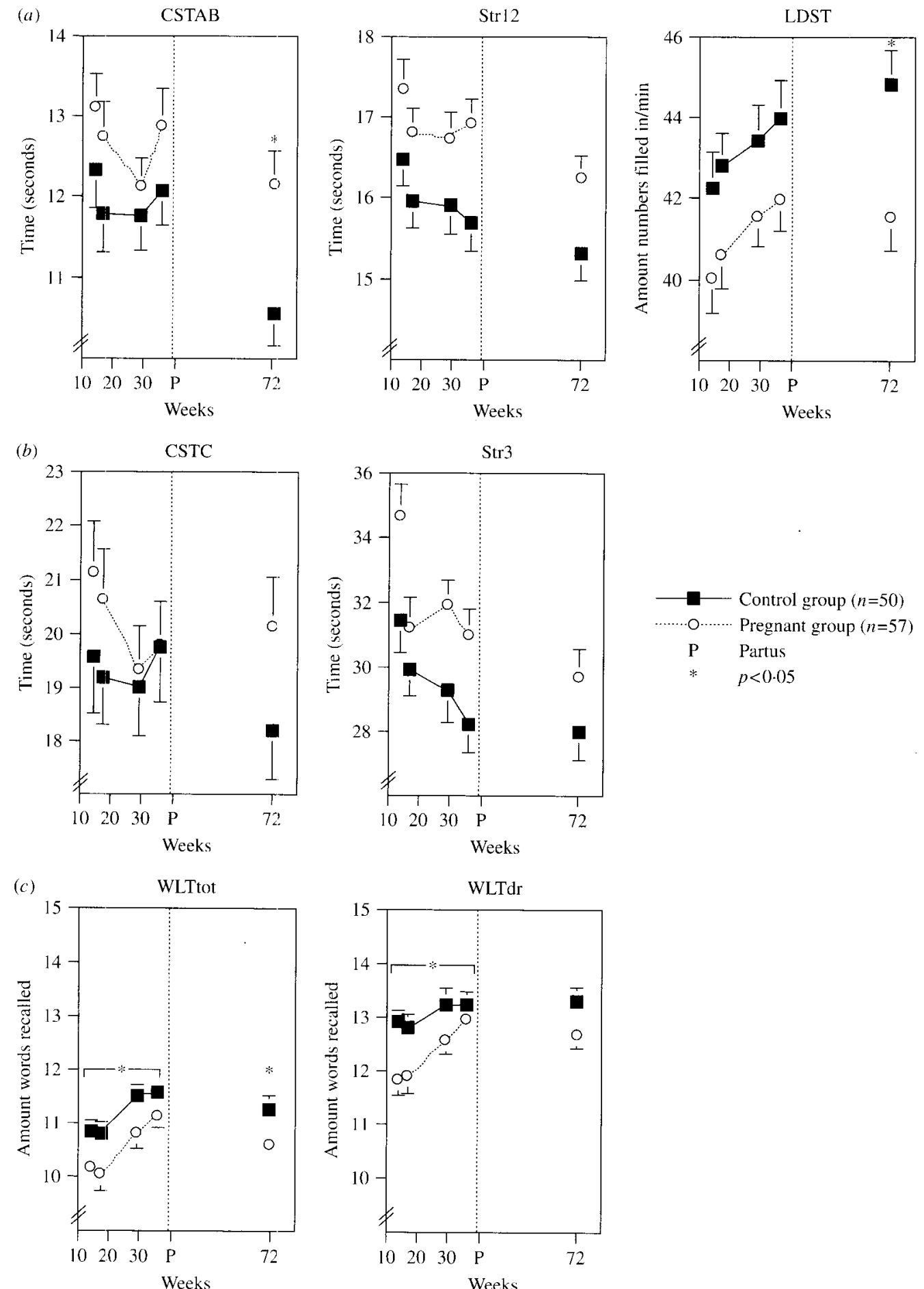

Fig. 1. Average cognitive scores of the pregnant group versus the control group over the study period (mean \pm s.E.M.). (a) General speed. (b) complex speed: (c) memory. Higher score on speed tasks means longer time taken to complete the task. so lower performance in speed of information processing. CST. Concept Shifting Test: Str. Stroop Test: LDST. Litter Digit Substitution Test: WLT, Word Learning Test ; tot, total: dr, delayed recall. 
Table 2. Results of statistical analyses of the differences between the control and the pregnant group (p values)

\begin{tabular}{llccc}
\hline \multirow{2}{*}{ Aspect of cognition } & \multicolumn{1}{c}{ Test } & $\begin{array}{c}\text { Pregnancy } \\
\text { group effect }\end{array}$ & $\begin{array}{c}\text { Pregnancy } \\
\text { group } \times \text { time effect }\end{array}$ & Postpartum \\
General speed & CSTAB (planning) & 0.206 & 0.749 & $0.010^{*}$ \\
& Str12 (selective attention) & 0.082 & 0.187 & 0.064 \\
Complex speed & LDST (coding) & 0.108 & 0.942 & $0.013^{*}$ \\
& CSTC (planning) & 0.667 & 0.460 & 0.233 \\
Memory & Str3 (selective attention) & 0.081 & 0.111 & 0.276 \\
& WLTtol (encoding) & $0.026^{*}$ & 0.848 & $0.031^{*}$ \\
\hline
\end{tabular}

CST, Concept Shifting Test; Str, Stroop Test: LDST, Letter Digit Substitution Test: WLT. Word Learning Test; tot. total: dr, delayed recall.

Differences between the control group and the pregnant group were corrected for education level.

$* p<0.05$.

Substitution Test), which is comparable to the LDST, and the TM (Trail Making test) which is comparable to CST. The performance of these women was compared with that of 20 matched controls tested at comparable times. The pregnant group scored worse on the DSST, with the largest performance difference being found 48 hours after delivery. We observed a poorer performance on the LDST 32 weeks postpartum. In contrast to our study, Harris et al. (1996) did not find any effects on the speed of performance or planning as measured with the TM. However, there are methodological differences between the two studies. First, Harris et al. tested their pregnant subjects at three different locations (antenatal clinic, at bedside, at home), whereas we always tested the participants in their homes, according to a strict protocol (no family members, door-bell and telephone switched off, always at about the same time of the day). This was done to prevent any environmental differences and thus to reduce error variance. Second, Harris et al. had a small study sample, which could have affected the power to detect significant differences. Moreover, no parallel versions of the TM were used, which is essential because of procedural learning and the possibility that the subject remembers the pattern on both test sheets. In contrast, we included more participants and used the CST and LDST, which are tests that are procedurally identical to the TM and DSST but which have parallel versions and which are more sensitive in detecting possible differences (Vink \& Jolles, 1985).
We did not find pregnancy and early motherhood to be associated with differences in performance on complex speed tasks, i.e., not with higher aspects of cognitive functioning, such as concept shifting ability and planning. This suggests that changes in motherhood are confined to 'general speed' and do not extend to higher aspects of cognitive functioning. Thus, motherhood appears to compromise aspects of automatic but not controlled processing (e.g. Brand \& Jolles, 1987).

Concerning memory performance during pregnancy, Keenan et al. (1998) observed in a longitudinal design a deterioration in the immediate as well as the delayed recall of paragraph-length in 10 pregnant women compared to 10 matched non-pregnant women. The difference, however, was only statistically significant in the third trimester. In an earlier cross-sectional study, Sharp et al. (1993) found significant deficits in explicit memory in the first and second trimesters of pregnancy. We found that pregnant women had a poorer performance than non-pregnant women on tasks of explicit memory performance in all trimesters.

Memory performance was also worse 32 weeks after delivery. Our findings are consistent with those of Casey et al. (1999), who reported that both pregnant and postpartum women experience significantly more signs of everyday forgetting than non-pregnant controls. However, these findings contrast with earlier objective studies showing that women perform better on memory tasks 26.5 days after delivery than during pregnancy (Buckwalter et al. 1999), and 
demonstrating that memory deficits are no longer apparent 2 or 3 days after delivery (Eidelman et al. 1993). These results suggest that memory impairment should no longer be present 32 weeks after delivery. It is probable that the inconsistency in results is due to methodological factors (for instance, the use, or not, of parallel versions of tests).

Thus, our findings suggest that different cognitive functions are affected differently during pregnancy and early motherhood. Although we did not address possible causes of these differences, both psychological and biological factors could be responsible. By 32 weeks after delivery, daily activities (and daily hassles) may have returned to 'normal' whereas normal biological functioning may not yet have been restored. There is evidence that mental functioning at this time takes place according to a "controlled processing' scheme, which is more time- and energy-consuming (Brand \& Jolles, 1987). In addition, the young mothers may have been affected by a lack of sleep or disturbed sleep patterns. Poor sleep may begin to have an impact at about 4 weeks postpartum (Kalil, 1987), when the psychosocial environment begins to return to normal, with daily hassles for the young mother, sometimes with an impending return to work and loss of an additional career. Indeed, Lee \& DeJoseph (1992) reported that postpartum women experienced sleeping problems and that very few young mothers felt highly energetic at work: in fact, most reported a high level of fatigue during the last week. Likewise, Lee \& Zaffke (1999) also reported on postpartum fatigue. It is probable that disturbed sleep, increased fatigue, and reduced mental energy are responsible for the reduced speed of information processing at 32 weeks postpartum that we observed. However, further studies are necessary to provide more in-depth information on the causative factor.

Apart from sleep and fatigue, mood changes could be responsible for the cognitive differences we found because cognitive energetic functions are compromised by depressed mood (Den Hartog et al. 2003). However, this is unlikely because we carefully screened our participants for any neuropsychological dysfunction, or indications for psychopathology, including depression. Moreover, 32 weeks after delivery, the women completed the Edinburgh Postpartum
Depression Scale (EPDS) to evaluate 6 months retrospectively the possible presence of depressive symptoms (Otto et al. 2003). It was shown that there were no significant differences in cognitive performance between the groups that were rated 'possibly depressed' or 'nondepressed'. In addition, Buckwalter et al. (1999) reported that the cognitive deficits they observed during pregnancy were statistically independent of mood disturbances associated with pregnancy. Our findings extend those of Buckwalter et al. by showing that memory deficits exist, which cannot be explained by mood status during pregnancy.

Biological factors may also be responsible for the poorer cognitive performance of the women during pregnancy and after delivery. For instance, breastfeeding causes hormonal changes that could influence cognitive performance. However, the cognitive function of women who breastfed their babies $(n=33)$ was not different from that of the women who bottle-fed their babies $(n=20)$.

Another biological explanation concerns changes in hormone levels. Higher oestrogen levels are usually associated with better cognitive performance (Hampson \& Kimura, 1988; Hampson, 1990; Kampen \& Sherwin, 1994; Robinson et al. 1994). This is in contrast with our study, where we found that women had a poorer memory performance during pregnancy, a state characterized by high oestrogen levels. Theoretically, it is possible that there is a threshold level for oestrogen below which it has positive effects and above which it has negative effects on cognition. Very high circulating levels of steroid hormones during pregnancy could have a negative effect on memory performance, which according to some studies can be an adaptive advantage of pregnancy in order to forget the less pleasant effects of childbirth (Russell et al. 2001). However oestrogen levels decrease immediately after delivery, whereas we did not see a change in memory performance. Progesterone may have adverse effects on cognition (Rice et al. 2000), but again progesterone levels decrease after delivery. Thus, the changes in cognitive performance we found do not parallel the hormonal changes generally found. Buckwalter et al. (1999) also found that a peripartal memory deficit could not be explained by the dramatic changes in circulating 
steroid hormones. More studies of the role of reproductive hormones on maternal cognition are needed before clear conclusions can be drawn.

Alternative biological factors of interest are the essential fatty acids and their longer-chain polyunsaturated derivatives (LCPUFAs) docosahexaenoic acid and arachidonic acid, which are important building blocks of cell membranes, especially those of the central nervous system (Svennerholm, 1968; Sastry, 1985). Because of their role in the reactivity of nervous tissue, it is plausible that a diminished availability of LCPUFAs, as suggested by the decrease of plasma LCPUFAs during pregnancy (Al et al. 1995), affects nervous function and hence cognition. Further research is necessary to elucidate the role of the changing fatty acid status during pregnancy in cognitive functioning.

Our study had a longitudinal controlled design, involved a large sample, and used parallel test versions, but it also had some weaknesses. Although we showed that memory performance was poorer in pregnant than in non-pregnant women, several factors not associated with pregnancy could be responsible for this association. Among these, selection bias is an important one. Although the two groups were similar in age and educational attainment, it is possible that even when not pregnant, the pregnant participants would have a poorer performance than the control women. However, the large sample size makes it improbable that the group of pregnant women scored worse on cognitive performance just by chance. Moreover, speed of information processing was similar at the start of the study, suggesting equal cognitive performance. In addition, most of the control women were friends or relatives of the pregnant women, so they originated from a similar social group. Furthermore, it is possible that our findings may underreport the actual effects of pregnancy since pregnant women experienced a life event (e.g. pregnancy delivery), whereas the women in the control group did not. Also, pregnancy entails numerous fluctuations in both biological and physiological variables, which makes it almost impossible to create a homogenous experimental group due to the individual variations that can affect any pregnant woman. Despite these inter-individual variations within the pregnant group, we still found significant differences in cognitive performance compared to the control group. Thus, the current study provides a strong indication that the pregnancy period is associated with changes in cognitive performance.

\section{ACKNOWLEDGEMENTS}

The authors thank all study participants, Arnold Kester and Nico Rozendaal for the statistical support, and Carel Thijs and Bart Scholtissen for critically reviewing this manuscript. We gratefully acknowledge the cooperation of the midwives and medical staff of the hospitals in our research area.

\section{DECLARATION OF INTEREST}

None.

\section{REFERENCES}

Al, M. D., van Houwelingen, A. C., Kester, A. D., Hasaart, T. H. de Jong, A. E. \& Hornstra, G. (1995). Maternal essential fatty acid patterns during normal pregnancy and their relationship to the neonatal essential fatty acid status. British Jounal of Nurition 74. 55-68.

Bohmen, Y.. Twijnstra, A. \& Jolles, J. (1992). Performance in the Stroop color word test in relationship to the persistence of symptoms following mild head injury. Acta Neurologica Scandimaria $85,116 \quad 121$.

Brand, N. \& Jolles, J. (1985). Learning and retrieval rate of words presented auditorily and visually. Joumal of Goneral Psichology. 112. 201210

Brand, N. \& Jolles, J. (1987). Information processing in depression and anxicty. Psichological Medicine 17, 145-153.

Brett. M. \& Baxendale, S. (2001). Motherhood and memory: a review. Psychoneuroendocrinology 26, 339-362.

Brindle, P. M., Brown, M. W., Brown, J., Griffith, H. B. \& Turner, G. M. (1991). Objective and subjective memory impairment in pregnancy. Psychological Medicine 21. 647-653.

Buckwalter, I. G., Stanczyk, F. Z. McCleary, C. A., Bluestein, B. W Buckwalter, D. K., Rankin, K. P., Chang, L. \& Goodwin, T. M. (1999). Pregnancy, the postpartum. and steroid hormones: effects on cognition and mood [published Erratum appears in Psychometroendocrinologi 1999, 24: 581]. Psichoneuroendo(rinolog) 24. 6984

Casey, P., Huntsdale, C., Angus, G. \& Janes, C. (1999). Memory in pregnancy. II: implicit, incidental, explicit. semantic, short-term. working and prospective memory in primigravid, multigravid and postpartum women. Joumal of Psichosomatic Obstetrics and Ginatecolog1 20,158-164.

Christensen, H., Poyser, C., Pollitt, P. \& Cubis, J. (1999). Pregnancy may confer a selective cognitive advantage. Joumal of Reproductive and Infant Psychology 17, 7-25.

Currie, C. E., Elton, R. A., Todd, J. \& Platt, S. (1997). Indicators of socioeconomic status for adolescents: the WHO Health Behaviour in School-aged Children Survey. Health Education Research 12. 385--397. 
de Bie, S. E. (1987). Standaardvagen 1987: Voorstellen voor uniformering van vraagstellingen naar achtergrondkenmorken en interviews [Standard questions 1987: Proposal for uniformisation of questions regarding background variables and interviews]. Leiden University Press: Leiden. The Netherlands.

de Groot, J. C., de Leeuw, F. E., Oudkerk, M., van Gijn, J., Hofman, A., Jolles, J. \& Breteler, M. M. (2002). Periventricular cerebral white matter lesions predict rate of cognitive decline. Annals of Neurology 52. 335-341.

de Groot, R. H. M., Adam, J., Jolles, J. \& Hornstra, G. (2004). Alpha-linolenic acid supplementation during human pregnancy does not effect cognitive functioning. Prostagkandins Leukotrienes and Essemial Faty' Acids 70, $41 \% 7$

de Groot, R. H. M., Hornstra, G., Roozendaal, N. \& Jolles, J. (2003). Memory performance, but not information processing speed, is compromised during early pregnancy. Joumal of Clinical and Evperimental Neuropsichologl 25. 482488.

Den Hartog, H. M., Derix, M. M., Van Bemmel, A. L., Kremer, B. \& Jolles, J. (2003). Cognitive functioning in young and middle-aged unmedicated out-patients with major depression: testing the effort and cognitive speed hypotheses. Psychological Medicine 33. $1443-1451$

Eidelman, A. I., Hoffmann, N. W. \& Kaitz, M. (1993). Cognitive deficits in women after childbirth. Obstetrics \& Gyecology 81. 764- 767.

Hampson, E. (1990). Estrogen-related variations in human spatial and articulatory-motor skills. Psrchomewoendocrinolog! 15 . 97. 111

Hampson, E. \& Kimura, D. (1988). Reciprocal effects of hormonal lluctuations on human motor and ferceptual-spatial skills. Behavioural Neufosciences 102, 456-459.

Harris, N. D., Deary, I. J., Harris, M. B., Lees, M. M. \& Wilson, J. A. (1996). Peripartal cognitive imparment: secondary to depression? British . onwnal of Health F'stchology 1. 127-136.

Houx, P. (1991). Cognitive Aging and Health-related Factors. Rijksuniversiteit Limburg: Maastricht.

Houx, P. J. \& Jolles, J. (1993). Age-related decline of psychomotor speed: effects of age, brain health, sex, and education. Percemion and Motor Skills 76, 195-211.

Jolles, J., Houx, P., Boxtel van, M. \& Ponds, R. (1995). Mactricht Aging Study: Determinants of Cogniate Aging. Neuropsych Publishers: Maastricht.

Kalil, K. (1987). Psychosocial stress, anxiety and pregnancy complications: issues for public policy. Pre-and Peri-Natal Psychologl 1 239-243.

Kampen, D. L. \& Sherwin. B. B. (1994). Estrogen use and verbal memory in healthy postmenopatusal women. Obstetrics \& G!necology 83, 9\%9-983.

Keenan, P. A., Yaldoo, D. T., Stress, M. E., Fuerst, D. R. \& Ginsburg, K. A. (1998). Explicit memory in pregnant women. American Journal of Obsteticis and Ginecology 179,731-737.

Klein, M., Houx, P. J. \& Jolles, J. (1996). Long-term persisting cognitive sequelae of traumatic brain injury and the effect of age. Joumal of Nervous and Montal Disonders 184 $459-467$.

Klein, M., Ponds, R. W., Houx, P. J. \& Jolles, J. (1997). Effect of test duration on alge-related differences in Stroop interference. Joumal of Clinical and Experimental Neuropsicholog! 19. $77-82$

Lahelma, E., Martikainen, P., Laaksonen, M. \& Aittomaki, A. (2004). Pathways between socioeconomic determinants of health. Joumal of Epickmiologr and Community Heaith 58 $327-332$.

Lee, K. A. \& DeJoseph, J. F. (1992). Sleep disturbances, vitality, and fatigue among a select group of employed childbearing women Birth 19.208.213

Lee, K. A. \& Zaffke, M. E. (1999). Longitudinal changes in fatigue and energy during pregnancy and the postpartum period. Journal of Obstetric Gineiologic \& Neonatal Nursing 28. 183191.

Lezak, M. D. (1995). Neuropsichological Assessment. Oxford University Press: New York.
Lynch, J. \& Kaplan, G. (2000). Socioeconomic position. In Social Epideniology (ed. L. F. Berkman and I. Kawachi), pp: 13-35. Oxford University Press: Oxford.

Moller, J. T., Cluitmans, P., Rasmussen, L. S., Houx, P., Rasmussen, H., Canet, J., Rabbitt, P., Jolles, J., Larsen, K., Hanning, C. D. Langeron, O., Johnson, T., Lauven, P. M., Kristensen, P. A Biedler, A., van Beem, H., Fraidakis, O. Silverstein, H. Biedler, A., van Beem, H., Fraidakis, O., Silverstein, J.H.,
Beneken, J. E. \& Gravenstein, J.S. (1998). Long-term postoperative cognitive dysfunction in the elderly ISPOCDI study. ISPOCD investigators. International Study of Post-Operative Cognitive Dysfunction. Lancet 351,857 861.

Morris, N., Toms, M., Easthope, Y. \& Biddulph, J. (1998). Mood and cognition in pregnant workers [see comments]. Applied Ergonomic: 29, $377-381$.

Otto, S. J., de Groot, R. H. M. \& Hornstra, G. (2003). Increased risk of postpartum depressive symptoms is associated with slower normalization after pregnancy of the functional docosahexaenoic acid status. Prostaglandins Leukotrienes and Essential Fatty Acids 69, 237-243.

Otto, S. J., van Houwelingen, A. C., Badart-Smook, A. \& Hornstra, G. (2001). Comparison of the peripartum and postpartum phospholipid polyunsaturated fatty acid profiles of lactating and nonlactating women. American Journal of Clinical Nutrition 73 , 1074-1079.

Parsons, C. \& Redman, S. (1991). Self-reported cognitive change during pregnancy. Australian Joumal of Advanced Nursing 9 $20-29$

Poser, C. M., Kassirer, M. R. \& Peyser, J. M. (1986). Benign encephalopathy of pregnancy. Preliminary clinical observations. Acta Neurologica Scandinavia 73, 39-43.

Rice, M. M., Graves, A. B., McCurry, S. M., Gibbons, L. E., Bowen, J. D., McCormick, W. C. \& Larson, E. B. (2000) Postmenopausal estrogen and estrogen-progestin use and 2-ycar rate of cognitive change in a cohort of older Japanese American women: the Kame Project. Archives of Internal Medicine $\mathbf{1 6 0}$. |64|-1649.

Robinson, D., Friedman, L., Marcus, R., Tinklenterg, J. \& Yesavage, J. (1994). Estrogen replacement therapy and memory in older women. Journal of the American Geriatrics Socicty $\mathbf{4 2}$ 919-922.

Russell, J. A., Douglas, A. J. \& Ingram, C. D. (2001). Brain preparations for maternity-adaptive changes in behavioral and neurocndocrine systems during pregnancy and lactation. An overview. Progress in Brain Research 133, 1-38.

Sastry, P.S. (1985). Lipids of nervous tissue: composition and metabolism. Progress in Lipid Research 24, 69176.

Schneider, Z. (1989). Cognitive performance in pregnancy. Australian Jotwal of Adranced Nursing 6. 40-47.

Sharp, K., Brindle, P. M., Brown, M. W. \& Turner, G. M. (1993) Memory loss during pregnancy [see comments]. British Journal of Obstetrics and Grnaecologl 100. 209215

Silber, M., Almkvist, O., I,arsson, B. \& Uvnas-Moberg, K. (1990). Temporary peripartal impairment in memory and attention and its possible relation to oxytocin concentration. Life Sciences 47. $57-65$.

Smith, A. (1968). The symbol Digit Modalities Test: a neuropsychologic test for economic screening of learning and other cerebral disorders. Leaming Disorders 3, 83-91.

Stroop, J. (1935). Studies of interference in serial verbal reaction Joumal of Experimental Psychology 18, 643-662.

Svennerholm, L. (1968). Distribution and fatty acid composition of phosphoglycerides in normal human brain. Jounal of Lipid Research $9.570-579$

van Boxtel, M. P., Buntinx, F., Houx, P.J., Metsemakers, J. F., Knottnerus, A. \& Jolles, J. (1998). The relation hetween morbidity and cognitive performance in a normal aging population. Jownat of Gerontology Series. A: Biological Sciences and Medical Scionces 53, M147-M154.

Vink, M. \& Jolles, J. (1985). A new version of the Trail Making Test as an information processing task. Jounul of Clinical Neuropsychology 7. 162. 